\title{
Nutritionally Small-for-Dates Rats: Their Subsequent Growth, Regional Brain 5-Hydroxytryptamine Turnover, and Behavior
}

\author{
J. L. SMART, ${ }^{(42)}$ M. D. TRICKLEBANK, B. P. F. ADLARD, AND JOHN DOBBING
}

Department of Child Health, University of Manchester, The Medical School, Manchester, United Kingdom

\section{Extract}

Rats were subjected to nutritional growth retardation either from conception to 5 postnatal days of age (fetal and neonatal restriction (FNR) group), or from 5 to 25 postnatal days of age (infantile restriction (IR) group). The FNR group may serve as a model for the human small-for-dates baby.

At 20 weeks of age cerebellum, midbrain, and cerebrum were significantly reduced in weight by $4 \%, 5 \%$, and $4 \%$, respectively, in FNR animals when compared with controls. Only cerebellum and midbrain were affected in IR rats of the same age, but in both regions the percentage deficits $(8 \%$ and $9 \%$, respectively) were greater than in FNR animals. Both cerebellum and midbrain weighed significantly less in IR than in FNR rats.

The timing of nutritional growth retardation appeared to be of little consequence to the regional brain turnover of 5-hydroxytryptamine in adulthood. The rate of synthesis in the hippocampus of both FNR and IR animals was significantly faster $167 \%$ and $75 \%$, respectively) than in controls. The increased turnover could perhaps represent "overactivity" of those 5-hydroxytryptaminergic neurons terminating in the hippocampus.

Some differences in the behavior of the previously undernourished adult animals were also evident. On the fifth day of testing, control rats were most venturesome in the open field. Eighteen control rats left the edge zone within $2 \mathrm{~min}$, whereas only 8 FNR and 11 IR rats did so. Most animals froze immediately after a 7-sec exposure to a loud electric bell. The delay before moving about again differentiated the three groups. FNR rats took longest to move out of the area in which they froze.

\section{Speculation}

Lasting changes have been shown here in rats undernourished at a stage of development commonly implicated in the growth retardation of many human small-for-dates infants. It would therefore be unwise at this stage to conclude that such babies emerge unscathed from intrauterine growth retardation.

The subsequent growth and neurologic and intellectual outcome for human infants who are growth retarded in utero is currently receiving much attention. The difficulties in performing and interpreting such long term studies as are necessary are great and include, for example, those connected with the possible interaction of different postnatal environments with the effects of prenatal growth restriction. Animal experiments, however, allow these variables to be controlled in a systematic way.

An animal model has recently been proposed for the human small-for-dates baby, in which increasingly severe nutritional growth retardation is applied from conception to 5 days of postnatal age by underfeeding the mother $(5,33)$. At 5 days of age the rat has reached a stage of brain growth comparable with the human term baby (see Reference 5). At this time the young are fostered to a well nourished mother and subsequently receive a good nutrition to adulthood. These animals are referred to as the FNR group.

Such FNR rats do not grow to be as large as controls, despite an early phase of partial or even complete catch-up $(5,33)$. Their brains are uniformly small, insofar as the three major brain regions examined show similar deficits in weight; and they probably contain fewer synapses (33). In the present study a more detailed investigation was made of the brain architecture of FNR rats.

For a few days after their transfer from a low to a high plane of nutrition at 5 days of postnatal age, the FNR rats show evidence of retarded neurologic maturation, but they appear to make good these delays quite soon (5). However, there still remains the possibility of some lasting effects on behavior. In an attempt to assess some aspects of emotional behavior, observations were made during the present investigation on the behavior of adult rats in stressful situations.

Early undernutrition may also have some lasting effects on brain metabolism. For example, alterations in the activities of enzymes involved in the metabolism of certain neurotransmitters have been found in adult rats after early growth restriction $(1,3,21)$. However, in vivo transmitter turnover rates have not been investigated in such animals. The present study examines the regional brain turnover of 5-hydroxytryptamine (5-HT) in adult FNR rats. Cerebral 5-HT metabolism was chosen for investigation not only because of its probable importance to brain function, but also because disturbed peripheral metabolism of the monoamine is a feature of a variety of conditions involving mental handicap (26, $27,38)$.

In addition to well fed controls, another group of rats was undernourished from 5 to 25 postnatal days (IR animals) for comparison with the FNR animals.

\section{METHODS}

\section{RATS}

Details of environmental control and rearing conditions (34) and of nutritional treatments (5) have been described previously in detail. Undernourished maternal rats were restricted to approximately $50 \%$ of the food intake of controls throughout pregnancy and lactation. Litters were reduced to eight animals (five males, three females) at birth, and at 5 days of age were fostered in one of three ways: $(I)$ between control mothers (control young, C), (2) from a control to an underfed mother (IR young), and (3) from an underfed to a control mother (FNR young). All rats were fed ad libitum from weaning at 25 days of age. They were housed thereafter two or three per cage in single sex groups. Males only were used in the present study. Rats were weighed at birth (day 0 ), at 5, 25, and 35 days, fortnightly thereafter till 19 weeks of age, and again when killed at 20 weeks. 


\section{TESTING OF BEHAVIOR}

Twenty male rats were tested from each group. These were drawn from $11 \mathrm{C}, 10 \mathrm{FNR}$, and $6 \mathrm{IR}$ litters. The rats were tested in an open field at about 16 weeks of age and in a passive avoidance situation at about 19 weeks. They were caged singly 3 days before each test and remained so till the end of each test. Between tests the original groups were reconstituted.

The animal rooms were on a 12 -hr white light/12 hr red light cycle. Rats were tested during the first few hours of their red phase. They were removed to another room at this time for observation in white light.

Open Field Test. A 74-cm diameter open field was used (34). Intensity of illumination in the center at floor level was 1,000 lux. Each rat was placed at the edge of the field and observed for $2 \mathrm{~min}$ on each of 5 consecutive days. The following were recorded: the number of areas of the field entered, the frequency of rearing on the hind legs, the number of fecal boli deposited, and the time of the first excursion out of the edge zone.

Testing in the open field was continued beyond $2 \mathrm{~min}$ on the 5 th day to include a bell response test devised by Archer (8). Eight seconds after the end of the open field test a loud electric door bell was switched on and allowed to ring for $7 \mathrm{sec}$. The number of areas entered by the rat while the bell was ringing was noted and the length of time for which it froze (remained still) after the bell stopped ringing. The latter was scored as latency to move a paw, to move the head, and to leave the area where freezing occurred.

Passive Avoidance Test. The two-compartment box was as previously described (35), except that (l) the walls of both compartments were of aluminum, and (2) the floor of the "safe" compartment was of smooth, white, nonconducting material. Electric shocks of $200 \mathrm{~V}$ (peak amplitude) from a source resistance of $150 \mathrm{k} \Omega$ could be delivered through the grid floor in the other compartment.

Details of the experimental procedure are given elsewhere (35). Briefly, in test $I$ rats received a 2 -sec inescapable shock when they crossed from the safe to the shock compartment. In test 2, 1 day later, they were replaced in the safe compartment. Time taken to cross between compartments on test 1 and 2 and reaction to shock on test $l$ were recorded. Rats were observed during test 2 by closed circuit television to minimize disturbance by the experimenter.

\section{REGIONAL BRAIN WEIGHT AND TURNOVER OF} 5-HYDROXYTRYPTAMINE

At 20 weeks of age the regional brain turnover of 5-HT was determined by measuring accumulation of the amine after inhibition of its degrading enzyme, monoamine oxidase (25). Animals were decapitated at various time intervals $(0,30,60$, or $90 \mathrm{~min})$ after administration of tranylcypromine $(20 \mathrm{mg} / \mathrm{kg}$ body $\mathrm{wt}$, ip) in physiologic saline. They were killed between 9:00 and 12:00 AM to minimize possible diurnal changes in cerebral 5-HT metabolism $(19,29)$. Animals were disturbed as little as possible after injection.

Whole brain excepting olfactory lobes was removed, placed on a glass tile embedded in a solid $\mathrm{CO}_{2}$-ice mixture, and dissected into pons-medulla, cerebellum, hypothalamus, midbrain, hippocampus, striatum, and cerebrum. The dissection was performed as described by Glowinski and Iversen (17) except that the pons-medulla was separated by a cut from the middle of the interpeduncular nucleus emerging immediately anterior to the cerebellum. This region included the caudal third of the mesencephalon and contained, therefore, the majority of the 5-HTcontaining nerve cell bodies (13). "Midbrain" consisted of the remainder of the mesencephalon and the thalamus and subthalamus. Cerebrum comprised the cerebral hemispheres except for the striatum. The composition of all other regions was as described by Glowinski and Iversen (17).

Each sample was frozen as quickly as possible over solid $\mathrm{CO}_{2}$ before weighing, and stored at $-20^{\circ}$ until assayed for 5-HT by the spectrophotofluorometric method of Curzon and Green (12).
The rate of accumulation of 5-HT in each brain region was calculated using regression analysis. The amount of 5-HT accumulated in $60 \mathrm{~min}$, derived from the regression coefficient, was taken as an estimate of the rate of synthesis or turnover of the monoamine. Assessment of the significance of regression coefficients and of the differences between regression coefficients was achieved by multivariate analysis (28).

\section{RESULTS \\ BODY GROWTH}

IR rats, undernourished between 5 and 25 days of postnatal age, showed a body weight deficit of $59 \%$ at 25 days (Table 1).

Table 1. Mean body weights $( \pm S D)$ of rats ${ }^{1}$

\begin{tabular}{|c|c|c|c|c|c|}
\hline \multirow[t]{2}{*}{$\begin{array}{l}\text { Postnatal } \\
\text { age, days }\end{array}$} & \multicolumn{3}{|c|}{ Body weight, g } & \multicolumn{2}{|c|}{$\begin{array}{l}\% \text { Deficit } \\
\text { compared } \\
\text { with rats }\end{array}$} \\
\hline & $\mathrm{C}$ & FNR & IR & FNR & IR \\
\hline 0 (birth) & $\begin{array}{c}5.6 \pm 0.5 \\
(54)\end{array}$ & $\begin{array}{l}4.8 \pm 0.8^{2} \\
(53)\end{array}$ & $\begin{array}{l}5.5 \pm 0.4 \\
(29)\end{array}$ & 13 & \\
\hline 5 & $\begin{array}{c}11.6 \pm 1.5 \\
(54)\end{array}$ & $\begin{array}{c}7.6 \pm 1.8^{2} \\
(49)\end{array}$ & $\begin{array}{c}11.7 \pm 1.2 \\
(28)\end{array}$ & 34 & \\
\hline 25 & $\begin{array}{c}47.9 \pm 11.3 \\
(53)\end{array}$ & $\begin{array}{c}47.7 \pm 7.9 \\
(46)\end{array}$ & $\begin{array}{l}19.6 \pm 3.3^{2} \\
(23)\end{array}$ & & 59 \\
\hline 140 & $\begin{array}{c}382 \pm 45 \\
(37)\end{array}$ & $\begin{array}{c}353 \pm 44^{3} \\
(32)\end{array}$ & $\begin{array}{c}318 \pm 33^{4} \\
(20)\end{array}$ & 8 & 17 \\
\hline
\end{tabular}

'The number of animals is given in parentheses. Statistical analysis was by Student's $t$-test. C: control; FNR: fetal and neonatal restriction; IR: infantile restriction.

${ }^{2} P<0.001$ compared with each of the other groups.

${ }^{3} P<0.01$ compared with each of the other groups.

${ }^{4} P<0.001$ compared with $\mathrm{C}$ rats.

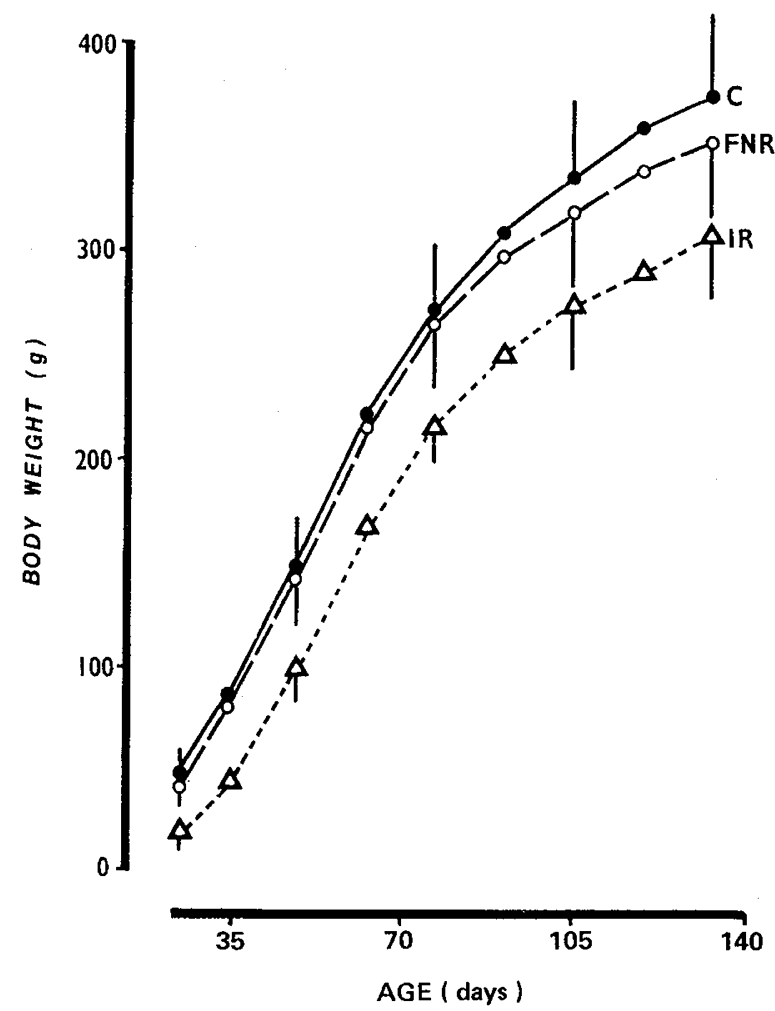

Fig. 1. Growth curves of control (C), fetal and neonatal restriction (FNR), and infantile restriction (IR) rats from weaning (25 days) till 20 weeks of age. Vertical bars represent standard deviations. 
Table 2. Regional brain weights at 20 weeks of age ${ }^{1}$

\begin{tabular}{|c|c|c|c|c|c|c|}
\hline & \multirow[b]{2}{*}{$\begin{array}{c}\text { C } \\
(n=37)\end{array}$} & \multirow[b]{2}{*}{$\begin{array}{c}\text { FNR } \\
(n=32)\end{array}$} & \multirow[b]{2}{*}{$\begin{array}{c}\mathrm{IR} \\
(n=20)\end{array}$} & \multicolumn{3}{|c|}{$P$ values } \\
\hline & & & & $\begin{array}{c}\text { C } \\
v s . \\
\text { FNR }\end{array}$ & $\begin{array}{c}\mathrm{C} \\
v s . \\
\mathrm{IR}\end{array}$ & $\begin{array}{c}\text { FNR } \\
v s . \\
\text { IR }\end{array}$ \\
\hline Brain $(\mathrm{g})$ & $1.804 \pm 0.085$ & $1.732 \pm 0.082$ & $1.742 \pm 0.062$ & $<0.001$ & $<0.005$ & n.s. \\
\hline Pons-medulla (mg) & $274 \pm 20$ & $271 \pm 18$ & $273 \pm 23$ & n.s. & n.s. & n.s. \\
\hline Cerebellum (mg) & $277 \pm 18$ & $266 \pm 14$ & $255 \pm 19$ & $<0.01$ & $<0.001$ & $<0.05$ \\
\hline Hypothalamus (mg) & $54.6 \pm 6.1$ & $52.9 \pm 6.4$ & $53.9 \pm 7.5$ & n.s. & n.s. & n.s. \\
\hline Midbrain (mg) & $238 \pm 22$ & $227 \pm 22$ & $217 \pm 14$ & $<0.05$ & $<0.001$ & $<0.05$ \\
\hline Hippocampus (mg) & $97.6 \pm 15.9$ & $92.8 \pm 13.6$ & $99.1 \pm 13.6$ & n.s. & n.s. & n.s. \\
\hline Striatum (mg) & $73.9 \pm 11.3$ & $69.3 \pm 8.2$ & $71.0 \pm 6.8$ & n.s. & n.s. & n.s. \\
\hline Cerebrum (mg) & $789 \pm 49$ & $754 \pm 52$ & $774 \pm 35$ & $<0.01$ & n.s. & n.s. \\
\hline Brain/body ratio (\%) & $0.478 \pm 0.060$ & $0.496 \pm 0.051$ & $0.554 \pm 0.061$ & n.s. & $<0.001$ & $<0.001$ \\
\hline $\begin{array}{l}\text { Cerebellum/brain } \\
\text { ratio }(\%)\end{array}$ & $15.3 \pm 0.6$ & $15.3 \pm 0.6$ & $14.6 \pm 0.7$ & n.s. & $<0.001$ & $<0.001$ \\
\hline $\begin{array}{l}\text { Midbrain/brain } \\
\text { ratio (\%) }\end{array}$ & $13.2 \pm 1.0$ & $13.1 \pm 1.0$ & $12.6 \pm 0.8$ & n.s. & $<0.02$ & $<0.05$ \\
\hline
\end{tabular}

${ }^{1} \mathrm{C}$ : control; FNR: fetal and neonatal restriction; IR: infantile restriction. Results (means $\pm \mathrm{SD}$ ) were compared using Student's $t$-test. n.s.: not significant.

Although IR rats subsequently grew at a rate comparable with control rats, they were still significantly smaller than both control and FNR animals at 20 weeks of age (Fig. 1, Table 1).

Immediately before nutritional rehabilitation from 5 days of age, FNR rats had a mean body weight deficit of $34 \%$ compared with controls. After rehabilitation from 5 days, FNR animals were indistinguishable from controls between 25 days and 13 weeks of age (Fig. 1). Beyond 13 weeks, however, the FNR group showed a smaller weight gain than controls and the significant difference at 15 weeks of age persisted until the animals were killed at 20 weeks (Table 1).

\section{BRAIN WEIGHT IN ADULTHOOD}

Brain weight in IR rats was significantly reduced (3\%), but only by as much as in FNR animals (4\%) even though the former group showed greater impairment of bodily growth (Tables 1 and 2 ). The brain weight to body weight ratio was raised significantly in IR animals, suggesting a sparing of brain growth relative to other organs and tissues by postnatal nutritional restriction.

The regional distribution of the brain weight deficit differed between the two early undernourished groups (Table 2). In FNR animals, cerebellum, midbrain and cerebrum were reduced in weight by $4 \%, 5 \%$, and $4 \%$ respectively. Only cerebellum and midbrain were affected in $\mathrm{IR}$ rats, but in both regions the percentage deficits ( $8 \%$ and $9 \%$, respectively) were greater than in FNR animals. Both cerebellum and midbrain weighed significantly less in IR than in FNR rats.

\section{REGIONAL TURNOVER OF 5-HYDROXYTRYPTAMINE}

Under the present assay conditions it was not possible to detect 5 -HT in cerebellum reliably. Even after $90 \mathrm{~min}$ of monoamine oxidase inhibition, no well defined peak of fluorescence characteristic of the 5-HT fluorophore could be demonstrated. The rate of accumulation of 5-HT in this region was not estimated, therefore.

However, in all other regions studied, the accumulation of 5-HT was linear over $90 \mathrm{~min}$, and all regression coefficients for all groups of animals were highly significant $(P<0.001)$. In control animals, turnover decreased in the order: hypothalamus $>$ midbrain $>$ pons-medulla $>$ striatum $>$ cerebrum $>$ hippocampus, which correlates well with the regional distribution of tryptophan hydroxylase activity (14). This is the rate-limiting enzyme in the synthesis of 5-HT (24).

A test of the null hypothesis that the true regression lines of $C$, FNR, and IR animals were parallel (although not necessarily
Table 3. Regional brain 5-hydroxytryptamine (5-HT) turnover in adult male rats undernourished in early life ${ }^{1}$

\begin{tabular}{|c|c|c|c|c|}
\hline & \multicolumn{4}{|c|}{ Rate of 5 -HT accumulation, $\mathrm{ng} / \mathrm{hr} / \mathrm{g}$ tissue } \\
\hline & $\mathrm{C}$ & FNR & IR & $\begin{array}{l}F \text { (Degrees } \\
\text { of freedom) }\end{array}$ \\
\hline Pons-medulla & $510 \pm 42$ & $588 \pm 54$ & $654 \pm 60$ & $1.8068(2,64)$ \\
\hline Hypothalamus & $864 \pm 108$ & $876 \pm 78$ & $804 \pm 120$ & $0.1061(2,64)$ \\
\hline Midbrain & $534 \pm 84$ & $630 \pm 66$ & $576 \pm 90$ & $0.8417(2,62)$ \\
\hline Hippocampus & $240 \pm 60$ & $402 \pm 54$ & $420 \pm 54$ & $3.7380(2,62)^{2}$ \\
\hline Striatum & $492 \pm 72$ & $552 \pm 60$ & $672 \pm 66$ & $1.8420(2,55)$ \\
\hline Cerebrum & $378 \pm 42$ & $324 \pm 42$ & $396 \pm 24$ & $0.7095(2,63)$ \\
\hline
\end{tabular}

${ }^{1}$ Results are means \pm SE. Rats were killed $0,30,60$, or 90 min after receiving tranylcypromine $(20 \mathrm{mg} / \mathrm{kg}$ body $\mathrm{wt})$. There were five to seven animals at each time interval in each group. $F$ values are derived from multivariate analysis of the regression lines. C: control; FNR: fetal and neonatal restriction; IR: infantile restriction.

${ }^{2}$ Significant effect of treatment, $P<0.05$.

Table 4. 5-Hydroxytryptamine (5-HT) turnover in hippocampus: Comparison of slopes of regression lines for control $(C)$, fetal and neonatal restriction $(F N R)$, and infantile restriction $(I R)$ rats $^{1}$

\begin{tabular}{|c|c|c|c|c|}
\hline Group & Equation of line & $\begin{array}{l}\text { Degrees } \\
\text { of } \\
\text { freedom }\end{array}$ & vs. C, $t$ & $v s$. FNR, $t$ \\
\hline $\mathrm{C}$ & $y=0.9658+0.003770 x$ & 62 & & \\
\hline FNR & $y=0.8606+0.006746 x$ & 62 & $2.29^{2}$ & \\
\hline IR & $y=0.8396+0.007005 x$ & 62 & $2.38^{2}$ & 0.19 \\
\hline
\end{tabular}

${ }^{1} \mathrm{y}=$ concentration of 5 -HT (micrograms per $\mathrm{g}$ tissue); $\mathrm{x}=$ time after administration of tranylcypromine (minutes). $t$ values were obtained by direct examination of the linear model involved (28).

${ }^{2} P<0.05$.

coincident) for each region gave an $F$ value of 3.738 , on 2 and 62 degrees of freedom for the hippocampus $(P<0.05$, Table 3$)$. That is, the three lines were not parallel; their slopes differed significantly. Further analysis of this data (Table 4) shown graphically in Figure 2, revealed a significant difference in slope between control and FNR $(P<0.05)$ and between control and IR animals 


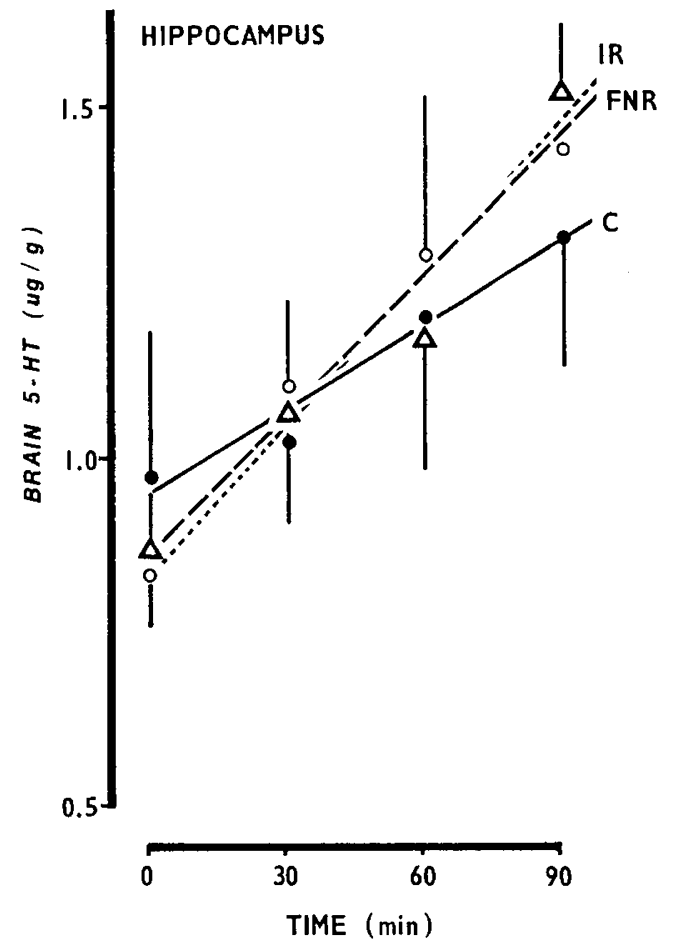

Fig. 2. Concentration of 5-hydroxytryptamine (5-HT) in the hippocampus at various time intervals after administration of tranylcypromine in control $(C)(-)$, fetal and neonatal restriction $(F N R)$ i (- - $)$, and infantile restriction $(I R) \quad(---)$ animals. Vertical bars represent standard deviations. There were five to seven animals at each time interval in each group. Lines were fitted by regression analysis.

$(P<0.05)$. There was no significant difference between IR and FNR rats. The turnover of 5-HT in the hippocampus of both FNR and IR animals was therefore significantly faster than in control animals. Contrary to previous and less appropriate statistical analysis of these results (37), smaller differences in turnover in the striatum and pons-medulla were not significant.

\section{OPEN FIELD TEST}

Results for the five 2-min sessions in the open field were subjected to a two-way (treatments and days) analysis of variance with repeated measures (39). Areas entered, frequency of rearing, and fecal boli deposited all declined across days $(F=117.04$, $P<0.001 ; F=29.05, P<0.001$; and $F=4.74, P<0.01$, respectively; degrees of freedom 4, 228 in all cases). There was no significant effect of treatment on the above three measures, although the IR rats tended to rear most often and to deposit most fecal boli. None of the interaction components of variance was significant.

Latency to leave the edge of the open field did not differ between groups till day 5 , when the $\mathrm{C}$ rats were the most venturesome. Eighteen $\mathrm{C}$ rats left the edge zone within $2 \mathrm{~min}$, whereas only 8 FNR $(P<0.005)$ and $11 \mathrm{IR}$ rats did so $\left(P<0.05\right.$, both $\chi^{2}$ tests corrected for continuity).

The typical response to the bell was for the rat to dash frantically about the open field for as long as the bell was ringing, then to freeze immediately that it stopped ringing. Some seconds later it would move its head, then a paw, and eventually begin cautiously to walk about again. The delay before performing the last response differentiated the three groups. Seven FNR rats took more than $200 \mathrm{sec}$ to move out of the area in which they froze, whereas no $\mathrm{C}(P<0.025)$ and only one IR animal took that long $\left(P<0.05\right.$, both $\chi^{2}$ tests corrected for continuity).

\section{PASSIVE AVOIDANCE TEST}

There were no significant differences between groups on any measure of behavior recorded in the passive avoidance situation (Mann-Whitney U-tests).

\section{DISCUSSION}

The present results confirm that a relatively mild degree of growth retardation before 5 days of age in rats results in a small but highly significant reduction in body weight in later life $(5,33)$. This permanent stunting can apparently occur even in rats which initially show complete "catch-up" with controls by the time of weaning. The later fall-off in growth occurred from about 12 weeks of age (Fig. 1), somewhat later than in a previous experiment (5).

Furthermore, it seems clear that FNR rats show a small but permanent impairment in brain growth. The deficit in brain size was similar to that in body weight, in marked contrast to IR rats which were typical of postnatally undernourished rats in showing brain "sparing" (high brain to body ratio) as adults. Undernutrition to 5 days of age appeared to have a fairly uniform effect on the later growth of different brain regions. This was again in contrast to IR animals where a selective effect on cerebellum and midbrain was found. These findings in the brain accord well with the effects of inhibitors of DNA synthesis (hydroxyurea, cytosine arabinoside) when given to fetal or postnatal rats $(2,4)$.

The timing of nutritional growth retardation appeared to be of little consequence to the regional brain turnover of 5-hydroxytryptamine. The rate of synthesis of the monoamine was significantly increased by approximately the same amount in the hippocampus of both FNR and IR animals. The increased turnover could perhaps represent "overactivity" of those 5-hydroxytryptaminergic neurons terminating in the hippocampus. However, this requires further investigation, perhaps by examining the turnover of labile "functional" pools of 5-HT (30). Nevertheless, it is possible that altered hippocampal 5-HT metabolism may play some part in the generation of the behavioral abnormalities of FNR animals, especially in view of the evidence of an involvement of 5-hydroxytryptaminergic systems in the regulation of emotional behavior (for review see Reference 11).

Changes in neurotransmitter metabolism in previously undernourished animals might be mediated through secondary nonnutritional factors. A number of endocrine systems are important in brain development and it is possible that hormonal imbalance in early life might permanently affect aspects of brain metabolism. For example, growth-retarded suckling rats show a high production of corticosteroids $(6,36)$, as do malnourished children (7). The hippocampus may be a major target for circulating corticosteroids $(22,23)$, and under certain circumstances corticosteroids may influence brain 5-HT metabolism (9). Thus it seems possible that in growth-retarded animals, hippocampal 5-HT metabolism may have been permanently altered by early exposure to abnormal corticosteroid concentrations.

The overall impression of the behavior of the FNR rats was that they differed little from controls in the situations described in the present paper, except that there were some indications of what might be called greater "timidity." Fewer of them ventured away from the edge of the open field on day 5 , and they were slower to start moving about again after the bell. There are no strictly comparable animal studies to which these findings can be related. The most relevant are probably those in which rats have been much more severely growth-retarded until birth and well nourished thereafter. These experiments, however, do not provide a wholly appropriate model for the small-for-dates baby. The growth restriction is probably too severe too soon (15). Human fetal growth is at its fastest in the third trimester and it is principally then that intrauterine growth retardation due to restriction of placental transmission is thought to occur.

Rats are born at a stage of brain development comparable with the human fetus at midterm, and growth restrictions as severe as $20 \%$ are unlikely to have occurred by that time (16). It could be argued that confining growth restriction to the period from birth to 5 postnatal days would have provided an even more realistic model for the small-for-dates baby than the one actually used. However, even with fostering to a mother underfed throughout pregnancy, there would be a delay while fetal reserves were metabolized before the undernutrition would become effective.

Simonson and her colleagues $(18,20,31)$ report considerable 
differences in the behavior of adult rats as a result of prenatal growth restriction, imposed by underfeeding the mother. Their rats are slower to set off from the start point in open field and maze situations, less active, less efficient at learning the route through a maze, and more inhibited by experience of electric shock. The tendency for our FNR rats to be more "timid" certainly fits this general pattern, although their deficiency was very much less. Unfortunately Simonson and her colleagues give no birth weights in any of these papers. However, Chow and Stephan (10) quote birth weights from eight separate experiments in which the mother rats were underfed as in the behavioral studies mentioned above. The mean birth weight deficit was rather more than $20 \%$. The animals in the present experiment, whose weight deficit widened from $13 \%$ at birth to $34 \%$ at 5 postnatal days, probably provide a more realistic model for the small-for-dates human baby.

Permanent changes have been shown here in rats undernourished at a stage of development commonly implicated in the growth retardation of many human small-for-dates infants. It would therefore be unwise at this stage to conclude that such babies emerge unscathed from intrauterine growth retardation.

\section{SUMMARY}

Developing rats were growth retarded by underfeeding their mothers either from conception to 5 postnatal days (FNR rats) or from 5 to 25 postnatal days (IR rats). All young were fostered at 5 days and all were fed ad libitum from 25 days. The FNR young had a body weight deficit of $34 \%$ at 5 days, and are taken to be a model for the human small-for-dates term baby. Their bodily growth caught up with that of well nourished controls by 25 days, but fell away in early adulthood, such that by 20 weeks they again had a significant body weight deficit. Their ultimate brain growth was also impaired, especially that of the cerebrum, cerebellum, and midbrain. Whole brain weight was lower in IR rats also, but no lower than in FNR rats despite the greater body weight deficit of the IR rats. Turnover of the neurotransmitter 5-HT was found to be increased in the hippocampus of both FNR and IR animals. In tests of emotional behavior using an open field, adult FNR rats appeared to be more timid than controls. They were slower to start to explore the center of the field and more inhibited by the loud ringing of a bell.

\section{REFERENCES AND NOTES}

1. Adlard, B. P. F., and Dobbing, J.: Vulnerability of developing brain. 8. Regional acetylcholinesterase activity in the brains of adult rats undernourished in early life. Brit. J. Nutr., 28: 139 (1972).

2. Adlard, B. P. F., and Dobbing, J.: Maze learning by adult rats after inhibition of neuronal multiplication in utero. Pediat. Res., 9: 139 (1975).

3. Adlard, B. P. F., Dobbing, J., Lynch, A., Balazs, R., and Reynolds, A. P.: Effect of undernutrition in early life on glutamate decarboxylase activity in the adult brain. Biochem. J., I30: 12P (1972).

4. Adlard, B. P. F., Dobbing, J., and Sands, J.: A comparison of the effects of cytosine arabinoside and adenine arabinoside on some aspects of brain growth and development in the rat. Brit. J. Pharmacol., 54: 33 (1975).

5. Adlard, B. P. F., Dobbing, J., and Smart, J. L.: An alternative animal model for the full-term small-for-dates human baby. Biol. Neonate, 23: 95 (1973).

6. Adlard, B. P. F., and Smart, J. L.: Adrenocortical function in rats subjected to nutritional deprivation in early life. J. Endocrinol., 54: 99 (1972).

7. Alleyne, G. A. O., and Young, V. H. : Adrenocortical function in children with severe protein-calorie malnutrition. Clin. Sci., 33: 189 (1967)

8. Archer, J.: Tests for emotionality in rats and mice: A review. Anim. Behav., 21: 205 (1973).

9. Azmitia, E. C., and McEwan, B. S.: Adrenocortical influence on rat brain tryptophan hydroxylase activity. Brain Res., 78: 291 (1974).

10. Chow, B. F., and Stephan, J. K.: Fetal undernourishment and growth potential. Nutr. Rep. Int., 4: 245 (1971)

11. Costa, E., and Sandler, M.: Serotonin-new vistas: Biochemistry and behavioural and clinical studies. In: Advances in Biochemical Psychopharmacology, Vol. 11 (Raven Press, New York, 1974).
12. Curzon, G., and Green, A. R.: Rapid method for the determination of 5-hydroxytryptamine and 5-hydroxyindoleacetic acid in small regions of rat brain. Brit. J. Pharmacol., 39; 653 (1970).

13. Dahlstrom, A., and Fuxe, K.: Evidence for the existence of monoamine-containing neurons in the central nervous system. I. Demonstration of monoamines in the cell bodies of brain stem neurons. Acta Physiol. Scand., 62: Suppl. 232 (1964).

14. Deguchi, T., and Barchas, J.: Regional distribution and developmental change of tryptophan hydroxylase activity in rat brain. J. Neurochem., 19: 927 (1972).

15. Dobbing, J.: The developing brain: A plea for more critical interspecies extrapolation. Nutr. Rep. Int., 7: 401 (1973).

16. Dobbing, J.: The later growth of the brain and its vulnerability. Pediatrics, 53:2 (1974).

7. Glowinski, J., and Iversen, L. L.: Regional studies of catecholamines in the rat brain. 1 . The disposition of $\left[{ }^{3} \mathrm{H} \mid\right.$ norepinephrine, $\left[{ }^{3} \mathrm{H}\right]$ dopamine and $\left[{ }^{3} \mathrm{H}\right]$ dopa in various regions of the brain. J. Neurochem., 13: 655 (1966).

18. Hanson, H. M., and Simonson, M.: Effects of fetal undernourishment on experimental anxiety. Nutr. Rep. Int., 4: 307 (1971).

19. Héry, F., Rouer, E., and Glowinski, J.: Daily variations of serotonin metabolism in the rat brain. Brain Res., 43: 445 (1972).

20. Hsueh, A. M., Simonson, M., Chow, B. F., and Hanson, H. M.: The importance of the period of dietary restriction of the dam on behavior and growth in the rat. J. Nutr., 104: 37 (1974).

21. Im, H. S., Barnes, R. H., and Levitsky, D. A.: Postnatal malnutrition and brain cholinesterase in rats. Nature (Lond.), 233: 269 (1971).

22. Knizley, H.: The hippocampus and septal area as primary target sites for corticosterone, J Neurochem., 19: 2737 (1972).

23. McEwan, B. S., Weiss, J. M., and Schwartz, L. S.: Uptake of corticosterone by rat brain and its concentration by certain limbic structures. Brain Res., 16: 227 (1969).

24. Moir, A. T. B., and Eccleston, D.: The effects of precursor loading in the cerebral metabolism of 5-hydroxyindoles. J. Neurochem., 15: 1093 (1968).

25. Neff, N. H., Lin, R. C., Ngai, S. H., and Costa, E.: Turnover rate measurements of brain serotonin in unanaesthetised rats. Advan. Biochem. Psychopharmacol., $l: 91$ (1969).

26. Pare, C. M. B.: 5-Hydroxyindoles in phenylketonuric and non-phenylketonuric mental defectives. Advan. Pharmacol., 6B: 159 (1968).

27. Pare, C. M. B., Sandier, M., and Stacey, R. S.: 5-Hydroxyindoles in mental deficiency. J. Neurol. Neurosurg. Psychiat., 23: 341 (1960).

28. Rao, C. R.: Linear Statistical Inference and Its Applications (Wiley, New York, 1965).

29. Scheving, L. E., Harrison, W. H., Gordon, N. P., and Pauly, J. E.: Daily fluctuation (circadian and ultradian) in biogenic amines of the rat brain. Amer. J. Physiol., 214: 166 (1968).

30. Shields, P. J., and Eccleston, D.: Evidence for the synthesis and storage of 5-hydroxytryptamine in two separate pools in the brain. J. Neurochem., 20:881 (1973).

31. Simonson, M., Stephan, J. K., Hanson, H. M., and Chow, B. F.: Open field studies in offspring of underfed mother rats. J. Nutr., 101: 331 (1971).

32. Smart, J. L., Adlard, B. P. F., and Dobbing, J.: Effect of maternal undernutrition and other factors on birth weight in the rat. Biol. Neonate, 20: 236 (1972).

33. Smart, J. L.. Adlard, B. P. F., and Dobbing, J.: Further studies of body growth and brain development in "small-for-dates" rats. Biol. Neonate, 25: 135 (1974).

34. Smart, J. L., and Dobbing, J.: Vulnerability of developing brain. II. Effects of early nutritional deprivation on reflex ontogeny and development of behaviour in the rat. Brain Res., 28: 85 (1971).

35. Smart, J. L., Dobbing, J., Adlard, B. P. F., Lynch, A., and Sands, J.: Vulnerability of developing brain: Relative effects of growth restriction during the fetal and suckling periods on behavior and brain composition of adult rats. J. Nutr., 103: 1327 (1973).

36. Sobotka, T. J., Cook, M. P., and Brodie, R. E.: Neonatal malnutrition Neurochemical, hormonal and behavioural manifestations. Brain Res., 65:443 (1974).

37. Tricklebank, M. D., and Adlard, B. P. F.: Regional brain 5-hydroxytryptamine turnover in adult rats growth retarded in early life. Biochem. Soc. Trans., 2: 907 (1974).

38. Tu, J., and Partington, M. W.: 5-Hydroxyindole levels in the blood and CSF in Down's syndrome, phenylketonuria and severe mental retardation. Develop. Med. Child Neurol., 14: 457 (1972).

39. Winer, B. J.: Statistical Principles in Experimental Design (McGraw Hill, New York, 1962).

40. Dr. P. J. Laycock, Mathematics Department, University of Manchester Institute of Science and Technology, gave invaluable assistance with the statistical analysis.

41. The Medical Research Council (UK) supported this research and the National Fund for Research into Crippling Diseases (UK) gave additional financial assistance.

42. Requests for reprints should be addressed to: J. L. Smart, Ph.D., Department of Child Health, University of Manchester, The Medical School, Stopford Bidg. Oxford Rd., Manchester M13 9PT (UK).

43. Accepted for publication April 14, 1976. 